\title{
Statin induces apoptosis of human colon cancer cells and downregulation of insulin-like growth factor 1 receptor via proapoptotic ERK activation
}

\author{
HYUN JOO JANG, EUN MI HONG, SE WOO PARK, HYUN WOO BYUN, \\ DONG HEE KOH, MIN HO CHOI, SEA HYUB KAE and JIN LEE
}

\begin{abstract}
Division of Gastroenterology, Department of Internal Medicine, Dongtan Sacred Heart Hospital, Hallym University School of Medicine, Hwasung, Gyeonggi 445-170, Republic of Korea
\end{abstract}

Received March 17, 2015; Accepted April 8, 2016

DOI: $10.3892 / 01.2016 .4569$

\begin{abstract}
Insulin-like growth factor 1 (IGF-1) and IGF-1 receptor (IGF-1R) signaling plays an important role in tumor progression in patients with certain gastrointestinal tract cancers. In addition to lowering cholesterol in serum, statins have pleiotropic effects, including anti-oxidative, anti-inflammatory or anti-neoplastic effects. Therefore, the present study investigated whether statins could induce the apoptosis of colon cancer cells and regulate the expression of IGF-1R and its associated signaling pathways in the present study. It was demonstrated that simvastatin and pravastatin suppressed cell proliferation and induced cell death in human HT-29 cells, but simvastatin was more potent than pravastatin. Simvastatin induced apoptosis in a concentration-dependent manner. In addition, simvastatin suppressed the expression of IGF-1R and inhibited the activity of phosphorylated-extracellular signal-regulated kinase (ERK)1/2 and phosphorylated-Akt activated by IGF-1. Simvastatin and IGF-1 each stimulated the activity of phosphorylated ERK1/2. However, simvastatin inhibited cell proliferation and IGF-1 stimulated cell proliferation. Mevalonic acid and PD98059 reversed the ERK activation and apoptosis induced by treatment with simvastatin. It was concluded that simvastatin induces the apoptosis of human colon cancer cells and inhibits IGF-1-induced ERK and Akt expression via the downregulation of IGF-1R expression and proapoptotic ERK activation. Simvastatin may be beneficial for the treatment of colon cancer. The present study suggested that statin may possess therapeutic potential for the treatment of colon cancer.
\end{abstract}

Correspondence to: Professor Hyun Joo Jang or Professor Jin Lee, Division of Gastroenterology, Department of Internal Medicine, Dongtan Sacred Heart Hospital, Hallym University School of Medicine, 40 Sukwoo, Hwasung, Gyeonggi 445-170, Republic of Korea

E-mail: jhj1229@hallym.or.kr

E-mail: jinlee@hallym.or.kr

Key words: statin, insulin-like growth factor-1, ERK, colon cancer, apoptosis

\section{Introduction}

There are numerous microdomain-mediated intracellular signaling pathways that regulate cellular functions and act as selective transduction mediators that control interactions between internal and external environments of cells (1). The insulin-like growth factor 1 (IGF-1)/IGF-1 receptor (IGF-1R) system plays important roles in the carcinogenesis and progression of gastrointestinal (GI) cancers (2). After the ligands bind to the external subunit of the IGF-1R, a conformational change is induced in the trans-membrane $\beta$ subunits, resulting in autophosphorylation of cytoplasmic tyrosine kinase. IGF-1R subsequently phosphorylates intracellular substrates, including insulin receptor substrates 1 to 4 and Shc (2). These early events activate multiple signaling pathways, including the mitogen-activated protein kinase (MAPK), extracellular signal-regulated kinase (ERK) and phosphoinositide 3-kinase (PI3-K)/Akt-1 pathways $(3,4)$. These pathways then switch on several cellular functions, including anti-apoptosis, transcription, metabolism, proliferation and growth.

In normal cells, the IGF-1/IGF-1R system is regulated by multiple steps (5). The expression of growth hormone $(\mathrm{GH})$ is activated by $\mathrm{GH}$-releasing hormone (GHRH). GH then increases the secretion of IGFs and IGF-binding proteins (IGFBPs) from hepatocytes. Activation of IGF-1R is tightly regulated by the amount of the free form of its ligand. IGFBPs 1 to 6 circulate and modulate IGF activity by reducing the bioavailability of IGF to bind to the IGF-1R (2) Dysregulation of the IGF/IGF-1R system has been implicated in the proliferation of numerous tumors, such as gastric, pancreas, esophageal and colorectal cancer $(6,7)$. Exogenous IGF stimulates the proliferation of various cancer cells. In addition, overexpressed IGF-1R signals are also important in tumor dissemination through the control of adhesion, migration and metastasis $(8,9)$. There is known to be a positive feedback loop between the IGF/IGF-1R axis and matrilysin for the progression and invasion of GI cancers (2). Therefore, blocking IGF-1R inhibits tumor progression through several interruptions of IGF-1R-mediated functions, including the IGF-1R and matrilysin positive feedback system (2).

By contrast, statins are extremely popular drugs for lowering serum cholesterol levels by inhibiting 
3-hydroxy-3-methylglutaryl-coenzyme A (HMG-CoA) reductase. Previously, statins have been studied for their pleiotropic effects, including anti-inflammatory, anti-oxidant and anti-cancer effects. Statins reduce serum cholesterol levels by competitively inhibiting HMG-CoA reductase, the rate-limiting enzyme in the mevalonate pathway. Mevalonate, in addition to being involved in cholesterol synthesis, is also involved in the synthesis of isoprenyl proteins, dolichols and ubiquinone, which perform several key cellular functions, such as cell signaling, proliferation, growth and respiration. Certain previous studies have shown statins to be beneficial as anti-cancer drugs $(10,11)$. The antitumor effects of statins may be due to the inhibition of cell proliferation, promotion of apoptosis, inhibition of angiogenesis and prevention of metastasis.

Therefore, the present study investigated whether simvastatin induces apoptosis of human colon cancer cells and how statin affects IGF-1R and its associated signaling pathways in colon cancer cells.

\section{Materials and methods}

Materials. Dulbecco's modified Eagle's medium (DMEM), fetal bovine serum (FBS), trypsin, EDTA, penicillin and streptomycin were from Gibco (Thermo Fisher Scientific, Inc., Waltham, MA, USA). Pravastatin and simvastatin were from Calbiochem (Merck Millipore, Darmstadt, Germany). Human IGF-1 was from R\&D Systems, Inc. (Minneapolis, MN, USA). Rabbit polyclonal antibodies against p44/42 MAPK (Erk1/2; \#9102), phospho-p44/42 MAPK (Erk1/2; Thr202/Tyr204; \#9101), Akt (\#9272) and phospho-Akt (Ser473; \#9271) were from Cell Signaling Technology, Inc. (Danvers, MA, USA). $\beta$-actin (\#sc-130656), rabbit polyclonal anti-IGF-1R (\#sc-713) and goat anti-rabbit immunoglobulin $\mathrm{G}$ (IgG)-horseradish peroxidase (HRP; \#sc-2768) antibodies were from Santa Cruz Biotechnology, Inc. (Dallas, TX, USA). Amersham ECL Advance Western Blotting Detection kit was from GE Healthcare Life Sciences (Chalfont, UK).

Cell culture. Human HT-29 cells were provided by Dr C. S. Eun (Hanyang University College of Medicine, Seoul, Korea) and were cultured in DMEM with $4.5 \mathrm{~g} / 1$ glucose and $2 \mathrm{mM}$ glutamine supplemented with $10 \%$ FBS, $1.5 \mathrm{~g} / \mathrm{l}$ sodium bicarbonate, $100 \mathrm{IU} / \mathrm{ml}$ penicillin and $100 \mu \mathrm{g} / \mathrm{ml}$ streptomycin. The medium was changed twice a week and the cells were maintained in an incubator at $37^{\circ} \mathrm{C}$ with a $5 \% \mathrm{CO}_{2}$ atmosphere. The cells were subcultured when confluent (every 5-7 days) using trypsin $(2.5 \mathrm{~g} / \mathrm{l})$ and EDTA $(1 \mathrm{~g} / 1)$. Experiments were performed in serum-free medium containing $0.1 \%$ bovine serum albumin (BSA; Sigma-Aldrich, St. Louis, MO, USA).

Methyl thiazolyl tetrazolium (MTT) assay. Cell proliferation of HT-29 cells was measured using an MTT assay. The HT-29 cells were seeded with DMEM culture medium at a density of $5 \times 10^{4}$ cells $/ \mathrm{ml}$ in a 96 -well plate. Following incubation at $37^{\circ} \mathrm{C}$ for $24 \mathrm{~h}$, the cells were treated with various concentrations of pravastatin or simvastatin $(2.5-20 \mu \mathrm{M})$ in serum-free medium for 24 or $48 \mathrm{~h}$. MTT $(0.5 \mathrm{mg} / \mathrm{ml}$; Sigma-Aldrich) was then added to each well and incubated for an additional $4 \mathrm{~h}$ at $37^{\circ} \mathrm{C}$. Subsequent to removal of the medium, $100 \mu 1$ dimethyl sulfoxide was added to each well, and the plates were weakly agitated for $10 \mathrm{~min}$. The optical density (OD) was evaluated by DTX 880 Multimode Detector (Beckman Coulter, Brea, CA, USA) at $570 \mathrm{~nm}$. Each assay was performed in triplicate.

Cell cycle analysis. The HT-29 cells were seeded with the DMEM culture medium at a concentration of $1 \times 10^{4}$ cells/well into a 6-well plate and incubated for 24 or $48 \mathrm{~h}$. Cells were treated with simvastatin $(50 \mu \mathrm{M})$ for 48 or $72 \mathrm{~h}$. The cells were harvested with $0.25 \%$ trypsin-EDTA and washed with PBS. The cells were centrifuged twice at $1,400 \mathrm{x}$ g for $5 \mathrm{~min}$ and then fixed with in $1 \mathrm{ml}$ of $70 \%$ ethanol at $-20^{\circ} \mathrm{C}$ for $1 \mathrm{~h}$. Subsequent to centrifugation at $1,400 \mathrm{x}$ g for $5 \mathrm{~min}$, the supernatant was removed and cells were incubated with $1 \mathrm{ml}$ PBS containing $10 \mu \mathrm{l}$ RNase (10 $\mu \mathrm{g} / \mathrm{ml}$; Sigma-Aldrich) and $20 \mu \mathrm{l}$ propidium iodide ( $1 \mathrm{mg} / \mathrm{ml}$; Sigma-Aldrich) at $37^{\circ} \mathrm{C}$ for $1 \mathrm{~h}$. The cell cycle was analyzed using the FACSCalibur flow cytometer and CellQuest software (BD Biosciences, San Jose, CA, USA). Flow cytometry was used to determine the percentage of cells in each phase of the cell cycle.

Cell death assay. Cell apoptosis was assessed by the detection of mono-oligonucleosomes, which are histone-associated DNA fragments, using a Cell Death Detection ELISA ${ }^{\text {PLUs }}$ kit (\#11774425001; Roche Applied Science, Mannheim, Germany), according to the manufacturer's protocol. The HT-29 cells were seeded with the culture medium in a 96-well plate at a concentration of $1 \times 10^{4}$ cells/well and incubated at $37^{\circ} \mathrm{C}$ for $24 \mathrm{~h}$. The cells were treated with various concentrations $(2.5-20 \mu \mathrm{M})$ of pravastatin or simvastatin for 24 or $48 \mathrm{~h}$. Subsequent to removal of the medium, the cells were treated with $100 \mu \mathrm{l}$ lysis buffer for $30 \mathrm{~min}$ and centrifuged at $200 \mathrm{x} \mathrm{g}$ at $4^{\circ} \mathrm{C}$ for $10 \mathrm{~min}$. The supernatant, which consisted of the cell lysate solution, was placed in the streptavidin-coated microplate supplied with the kit. A mixture of the provided anti-histone-biotin and anti-DNA-POD antibodies were added to the cell lysate and incubated for $2 \mathrm{~h}$. Subsequent to washing the plate, $100 \mu \mathrm{l}$ of 2,2'-azinobis-3-ethyl-benzothiazoline-6-sulfonic acid substrate was added to each well of the plate for $20 \mathrm{~min}$. The absorbance at $405 \mathrm{~nm}$ was measured using a DTX 880 Multimode Detector (Beckman Coulter).

Caspase-3 activity assay. Caspase- 3 activity assay (BioVision, Mountain View, CA, USA) was used to measure caspase-3 activity, according to the manufacturer's protocol. The cells were plated on $60 \mathrm{~mm}$ dishes in culture medium at a concentration of $2 \times 10^{6}$ cells $/ \mathrm{ml}$ and treated with various concentrations of pravastatin or simvastatin $(5-50 \mu \mathrm{M})$ for $48 \mathrm{~h}$. Cells were washed with PBS and harvested with lysis buffer. Cells were kept on ice for $10 \mathrm{~min}$. The cell lysate was centrifuged at $12,000 \times \mathrm{g}$ at $4^{\circ} \mathrm{C}$ and supernatant was transferred to a new tube and stored on ice. Protein contents were analyzed using the Bradford assay (Sigma-Aldrich). Assays were performed in 96-well plates containing $90 \mu \mathrm{g}$ of protein in $50 \mu \mathrm{l}$ lysis buffer, and $5 \mu \mathrm{l}$ of $4 \mathrm{mM}$ DEVD-pNA was added to the protein samples. The samples were incubated at $37^{\circ} \mathrm{C}$ for $2 \mathrm{~h}$. Absorbance was measured at $405 \mathrm{~nm}$ using the DTX 880 Multimode Detector.

Western blotting. The cells were washed with PBS and harvested with radioimmunoprecipitation assay lysis buffer 

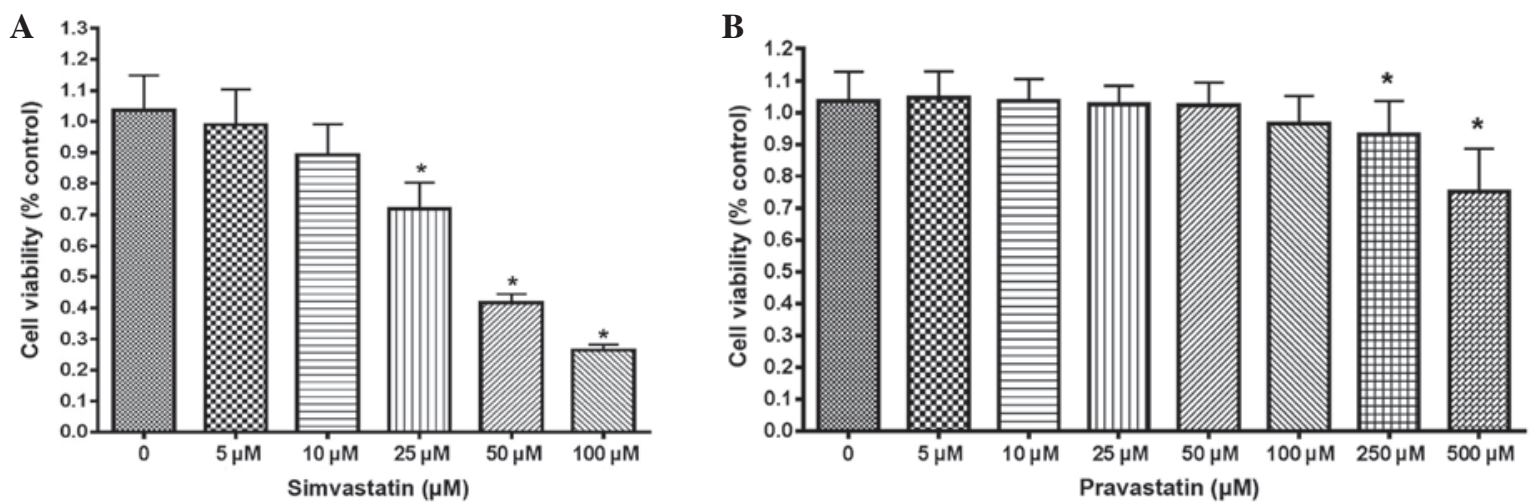

Figure 1. The effect of statins on cell proliferation. (A) Cell viability subsequent to treatment with various concentrations of simvastatin by MTT assay. The viability of HT-29 cells was reduced by simvastatin treatment in a dose-dependent manner. *P<0.001 vs. control. (B) Cell viability subsequent to treatment with various concentrations of pravastatin by MTT assay. The viability of HT-29 cells was reduced by pravastatin treatment in a dose-dependent manner. However, HT-29 cells were more resistant to treatment with pravastatin than treatment with simvastatin. ${ }^{*} \mathrm{P}<0.001$ vs. control. All results are expressed as the mean \pm standard deviation of at least 3 experiments. MTT, methyl thiazolyl tetrazolium.

containing $50 \mathrm{mM}$ Tris $(\mathrm{pH} 7.5), 150 \mathrm{mM} \mathrm{NaCl}, 1 \mathrm{mM}$ EDTA, $1 \%$ Triton $\mathrm{X}-100,1 \%$ sodium deoxycholate, $0.1 \%$ SDS, $1 \mu \mathrm{M}$ phenylmethylsulfonyl fluoride, $5 \mu \mathrm{g} / \mathrm{ml}$ aprotinin and $5 \mu \mathrm{g} / \mathrm{ml}$ leupeptin. Protein contents were analyzed using the Bradford assay (Sigma-Aldrich). Sodium dodecyl sulfate-polyacrylamide gel electrophoresis was performed with a $4 \%$ stacking gel and a $10 \%$ resolving gel, followed by transfer to nitrocellulose membrane (Bio-Rad Laboratories, Inc., Hercules, CA, USA). The membranes were blocked for $1 \mathrm{~h}$ at room temperature in blocking solution containing $5 \%$ skim milk in Tris-buffered saline with Tween-20 (TBS-T), which consisted of $200 \mathrm{mM}$ Tris, $500 \mathrm{mM} \mathrm{NaCl}(\mathrm{pH} 7.5)$ and $0.05 \% \mathrm{v} / \mathrm{v}$ Tween-20 (Sigma-Aldrich). The membranes were then incubated overnight at $4^{\circ} \mathrm{C}$ in $5 \%$ BSA solution, consisting of 5\% BSA in TBS-T, with the phosphorylated-p44/42 MAPK, non-phosphorylated-p44/42 MAPK, phosphorylated-Akt, non-phosphorylated-Akt or IGF-1R antibodies (dilution, 1:1,000). The membranes were washed with TBS-T and incubated with a goat anti-rabbit IgG-HRP antibody for $1 \mathrm{~h}$ at room temperature. The membranes were washed and developed using an Amersham ECL Advance Western Blotting Detection kit for $2 \mathrm{~min}$, and autoradiography was performed. The signal intensities for specific bands on the western blots were semi-quantified using ImageJ density analysis software (Version 1.43; National Institutes of Health, Bethesda, MA, USA).

Statistical analysis. Results from each experiment were expressed as the mean \pm standard deviation of three separate experiments. Data were analyzed by one-way analysis of variance and by Tukey's multiple comparisons test using GraphPad Prism software version 4.0 (GraphPad Software, Inc., La Jolla, CA, USA).

\section{Results}

Simvastatin suppresses cell proliferation in HT-29 cells. The proliferation of HT-29 cells was first examined by statins using an MTT assay. Simvastatin suppressed the proliferation of HT-29 cells in a dose-dependent manner (Fig. 1A). Cell proliferative activity was significantly suppressed at doses $>25 \mu \mathrm{M}$ simvastatin, compared with untreated control cells $(\mathrm{P}<0.001)$. However, HT-29 cells were more resistant to treatment with pravastatin than simvastatin, since the viability of HT-29 cells treated with pravastatin was significantly reduced at a dose of $250 \mu \mathrm{M}$, while the viability of cells treated with simvastatin was reduced at $25 \mu \mathrm{M}$ (Fig. 1B).

Simvastatin induces apoptosis via caspase-3 activation, downregulates the expression of B cell lymphoma-2 (Bcl-2) and upregulates the expression of Bcl-2-associated $X$ protein (Bax). The effect of statins on cell death was investigated using a cell death detection ELISA assay. Simvastatin significantly induced apoptosis in HT-29 cells at a dose of $>10 \mu \mathrm{M}$ simvastatin, compared with control cells, while pravastatin was not as effective as simvastatin for inducing cell death of HT-29 cells (Fig. 2A and B). Simvastatin also significantly increases caspase-3 activity in a dose dependent manner (Fig. 2C). Western blotting of the proapoptotic protein Bax and anti-apoptotic protein Bcl-2 was also examined. Simvastatin significantly upregulated the expression of Bax and downregulated the expression of Bcl-2 (Fig. 2D). These results suggest that simvastatin induces apoptosis of HT-29 cells.

Simvastatin induces G1-phase cell cycle arrest. Cell cycle analysis by flow cytometry was performed on HT-29 cells subsequent to 48 and $72 \mathrm{~h}$ treatment with simvastatin. The cell population in the G1 phase was increased by 9.45 and $20.39 \%$, respectively, compared with the control $(\mathrm{P}<0.05)$. These results demonstrated that simvastatin induced the arrest of colon cancer cells in the G1 phase (Fig. 3).

Simvastatin suppresses the expression of $I G F-1 R$ and IGF-1-induced ERK/Akt activation. The present study examined how simvastatin affects IGF-1R and its signaling pathways in HT-29 cells. Treatment with simvastatin significantly downregulated the expression of IGF-1R $\beta$ in a dose-dependent manner, compared with the untreated control cells (Fig. 4A). In addition, the present study examined the effect of simvastatin on the IGF-1R signaling pathway. HT-29 cells were pretreated with $10 \mu \mathrm{M}$ simvastatin for $24 \mathrm{~h}$ and then stimulated with $100 \mathrm{nM}$ IGF-1 for $15 \mathrm{~min}$. IGF-1 treatment alone stimulated 


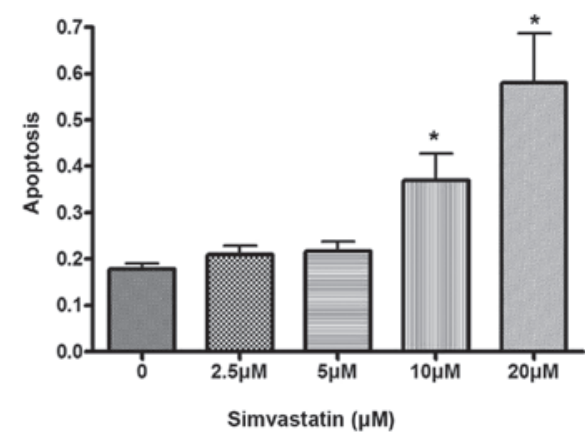

C

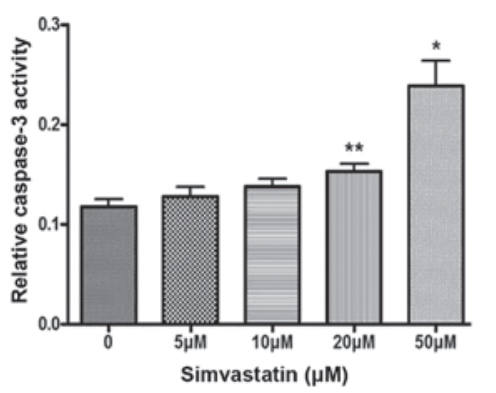

B

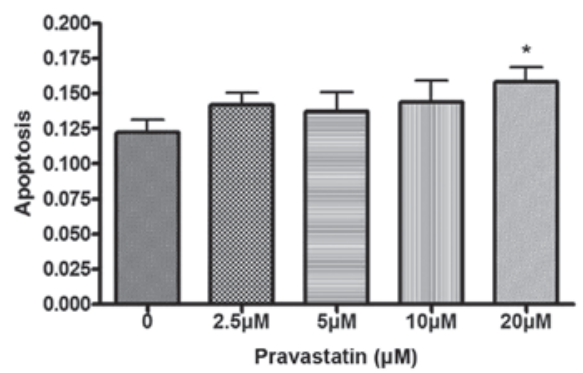

D

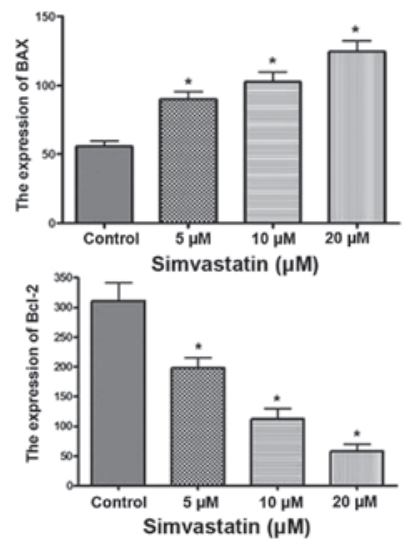

Figure 2. Effect of statins on apoptosis. (A) The effect of simvastatin on the death of HT-29 cells, as determined by cell death detection ELISA. "P<0.001 vs. control. (B) The effect of pravastatin on the death of HT-29 cells, as determined by cell death detection ELISA. "P<0.001 vs. control. (C) Caspase-3 activity subsequent to treatment with simvastatin for $48 \mathrm{~h}$. ${ }^{*} \mathrm{P}<0.001$ vs. control; ${ }^{* * *} \mathrm{P}<0.05$ vs. control. (D) The expression of Bcl- 2 and Bax subsequent to treatment with simvastatin $(10 \mu \mathrm{M})$ for $24 \mathrm{~h}$. "P<0.001 compared with control. ELISA, enzyme-linked immunosorbent assay; Bcl-2, B cell lymphoma-2; Bax, Bcl-2-associated $\mathrm{X}$ protein.
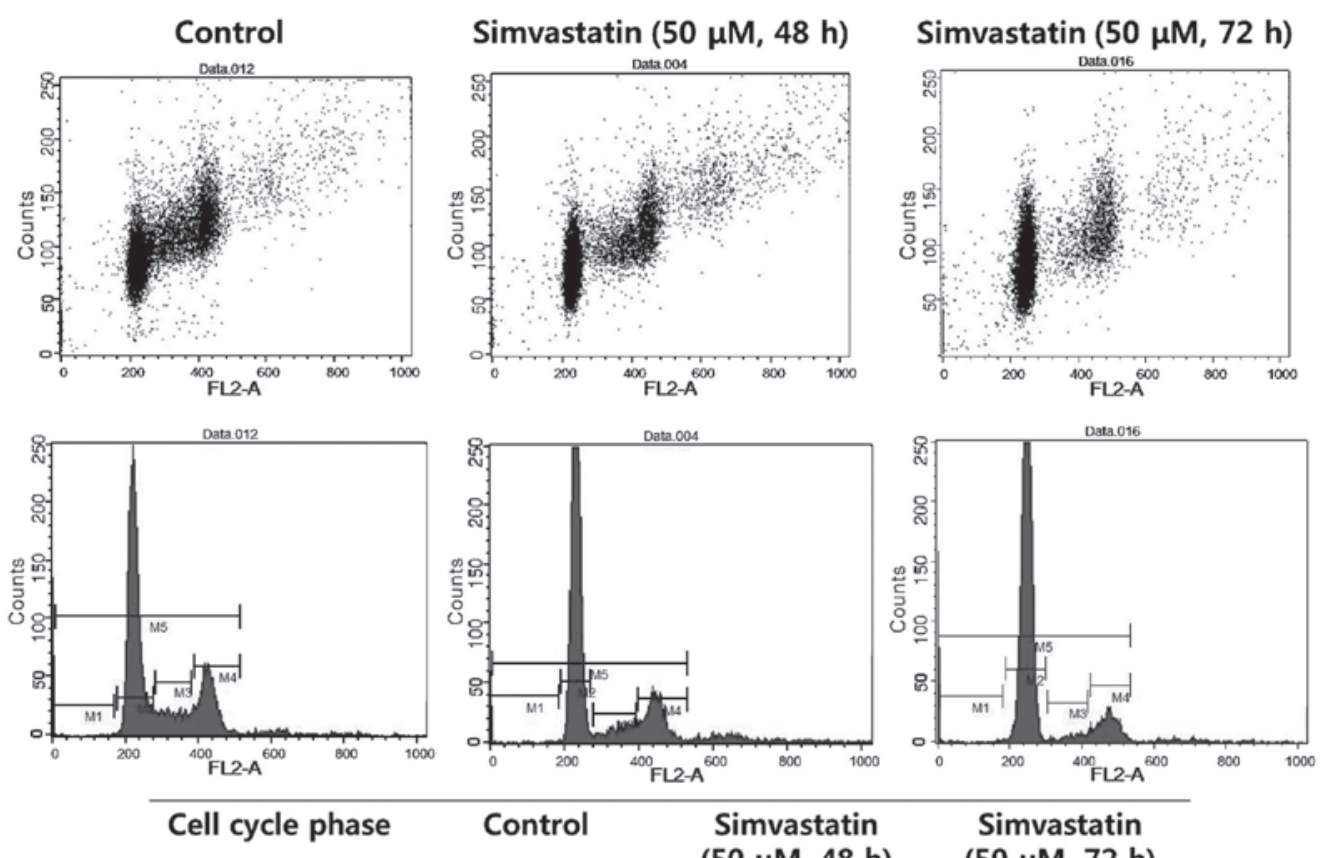

\begin{tabular}{cccc}
\hline Cell cycle phase & Control & $\begin{array}{c}\text { Simvastatin } \\
(\mathbf{5 0} \boldsymbol{\mu M}, \mathbf{4 8} \mathbf{h})\end{array}$ & $\begin{array}{c}\text { Simvastatin } \\
(\mathbf{5 0} \boldsymbol{\mu M}, \mathbf{7 2} \mathbf{~ h})\end{array}$ \\
\hline G0 (\%) & 0.73 & 1.34 & 2.65 \\
G1 (\%) & 61.65 & $71.10^{\star}$ & $82.04^{\star}$ \\
S (\%) & 14.50 & 9.11 & 3.48 \\
G2/M (\%) & 23.12 & 18.45 & 11.63 \\
\hline
\end{tabular}

Figure 3. The effect of simvastatin on cell cycle, as determined by flow cytometry. Treatment with simvastatin increased the cell population in the G1 phase compared with control in HT-29 cells. $\mathrm{P}<0.05$ vs. untreated control cells by analysis of variance with Tukey's multiple comparison test. 
A
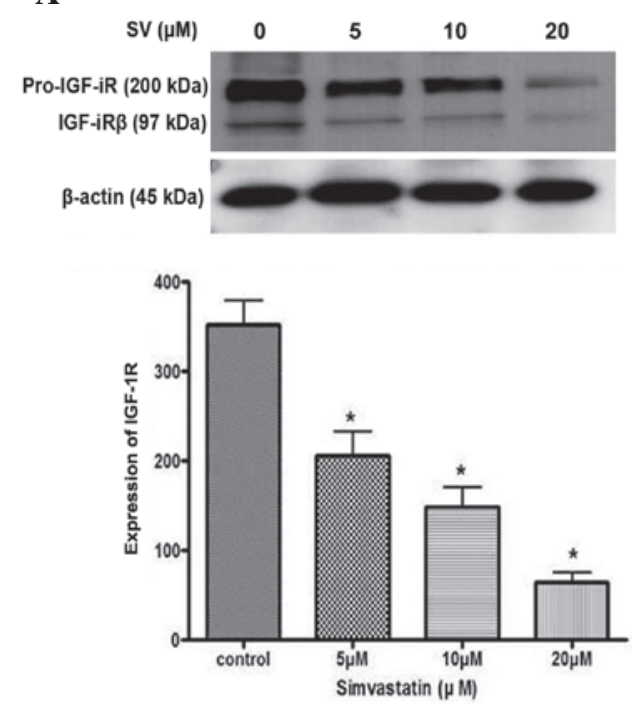

B
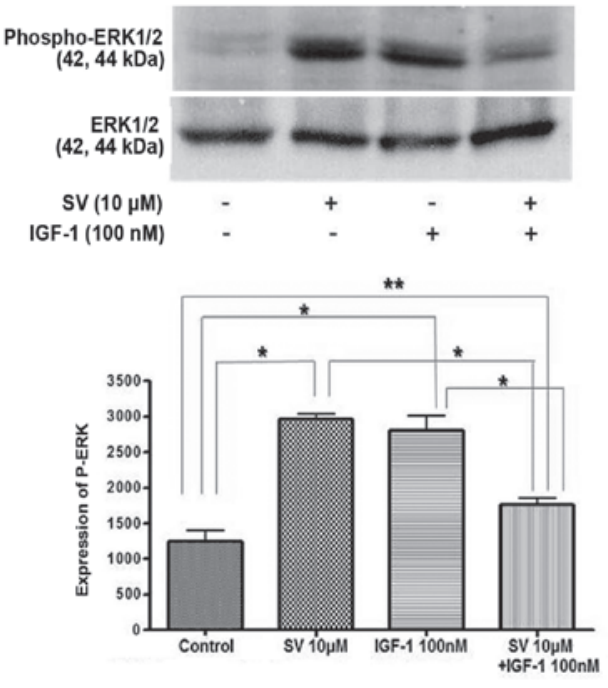

C
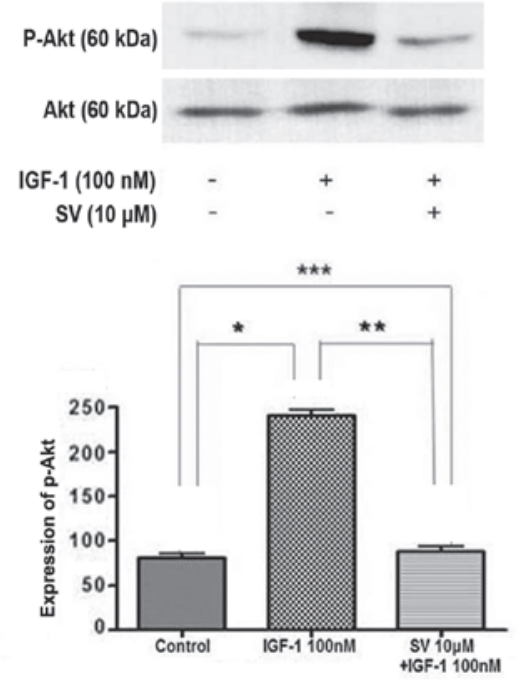

Figure 4. Effect of SV on IGF-1 receptor signaling pathway. (A) SV decreases the expression of IGF-1R in a dose-dependent manner. * $<0.001$ vs. untreated control cells. (B) SV and IGF-1 stimulated the expression of P-ERK. However, SV suppressed the expression of P-ERK induced by IGF-1 treatment. ${ }^{*} \mathrm{P}<0.001$ vs. untreated control cells; ${ }^{* *} \mathrm{P}<0.05$ vs. untreated control cells. (C) SV suppressed IGF-1-induced Akt activation. ${ }^{*} \mathrm{P}<0.001,100 \mathrm{nM}$ IGF-1 vs. untreated control cells; ${ }^{* *} \mathrm{P}<0.05,10 \mu \mathrm{M}$ SV + $100 \mathrm{nM}$ IGF-1 vs. untreated control cells; ${ }^{* * *} \mathrm{P}<0.001,10 \mu \mathrm{M}$ SV+100 nM IGF-1 vs. IGF-1 $100 \mathrm{nM}$. SV, simvastatin; IGF-1, insulin-like growth factor 1; ERK, extracellular signal-regulated kinase; P-ERK, phosphorylated-ERK.

ERK phosphorylation, which was significantly suppressed by simvastatin treatment. However, $10 \mu \mathrm{M}$ simvastatin alone also induced phosphorylated ERK activation in a similar manner to IGF-1 treatment (Fig. 4B).

For the next step, the same experiment was performed to examine Akt activation. First, IGF-1 induced Akt phosphorylation. IGF-1-induced phosphorylated Akt was also significantly suppressed subsequent to simvastatin treatment (Fig. 4C). These results indicate that simvastatin suppresses IGF-1-induced ERK and Akt activation in HT-29 cells.

Simvastatin induced proapoptotic ERK activation and antagonized IGF-1-induced anti-apoptotic ERK. To understand why ERK was activated by IGF-1 and simvastatin, the effect of mevalonic acid on the MAPK pathway was investigated. ERK activity was blocked with the MEK inhibitor PD98059. ERK activity and the degree of cell proliferation was then evaluated. As shown in Fig. 5A, treatment with simvastatin for $24 \mathrm{~h}$ stimulated sustained activation of phosphorylated ERK, which was reversed by treatment with mevalonic acid and PD98059. Apoptosis was induced by treatment with simvastatin, but this was fully reversed by pretreatment with mevalonic acid and partially reversed by pretreatment with PD98059 (Fig. 5B and C). This result indicates that simvastatin induced apoptosis through selective and sustained activation of proapoptotic ERK.

By contrast, IGF-1 induced phosphorylation of ERK, which peaked at 15 min subsequent to treatment with IGF-1, and led to cell proliferation, while simvastatin suppressed IGF-1-induced ERK activation and cell proliferation, which was also reversed by pretreatment with mevalonic acid (Fig. 5D). This result indicated that IGF-1 stimulated anti-apoptotic ERK phosphorylation, while simvastatin induced proapoptotic ERK activation and also antagonized IGF-1-induced anti-apoptotic ERK activation through sustained ERK phosphorylation.

\section{Discussion}

In the present study, it was demonstrated that simvastatin inhibited the proliferation of colon cancer cells and suppressed the expression of IGF-1R and IGF-1-induced ERK/Akt activation in HT-29 cells. To the best of our knowledge, the present study showed for the first time that simvastatin induced proapoptotic ERK and antagonized IGF-1-induced anti-apoptotic ERK in colon cancer cells.

IGF-1R is synthesized as a single precursor peptide that is cleaved into the $\alpha$ and $\beta$ chains, and is transported to the membrane fully assembled in the dimeric form, with two $\alpha$ chains and two $\beta$ subunits. Subsequent to transportation, the ligands bind to the subunits of IGF-1R, which is autophosphorylated to stimulate tyrosine kinase in the intracellular domain of the $\beta$ subunits (2-4). These early events activate multiple signaling pathways, including the MAPK, ERK and PI3-K/Akt-1 pathways. Overexpression of IGF-IR has been shown in numerous solid cancers and is associated with cancer progression and metastasis $(12,13)$. It has been reported that IGF-IR is overexpressed or over-activated in almost $80 \%$ of colon cancers $(14,15)$. In the present study, statins induced downregulation of the $\beta$ subunits of IGF-1R and suppressed the subsequent ERK and PI3-K/Akt activation induced by IGF-1 in HT-29 cells. These results indicate that statins could control the IGF-1R signaling pathway, which is important in the growth and metastasis of colon cancer.

Statins cause substantial reduction in the serum cholesterol level, other downstream mevalonate products (such as isoprenoid molecules, farnesyl pyrophosphate and geranylgeranylpyrophosphate, which are necessary for post-translational modification) and isoprenylation of a variety of proteins that are involved in cell motility, such as Ras and Rho $(11,16)$. Therefore, statins are considered to be plausible treatment options as lowering the cholesterol 

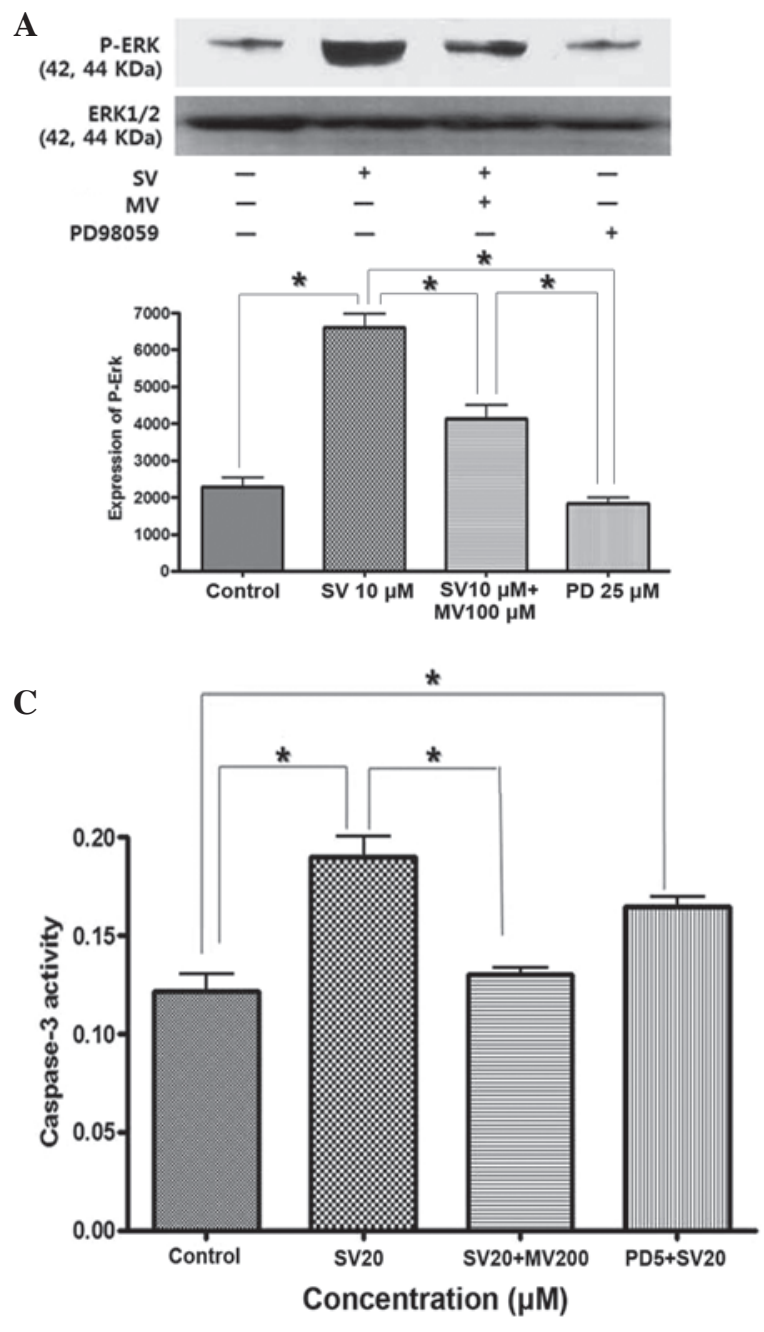

B

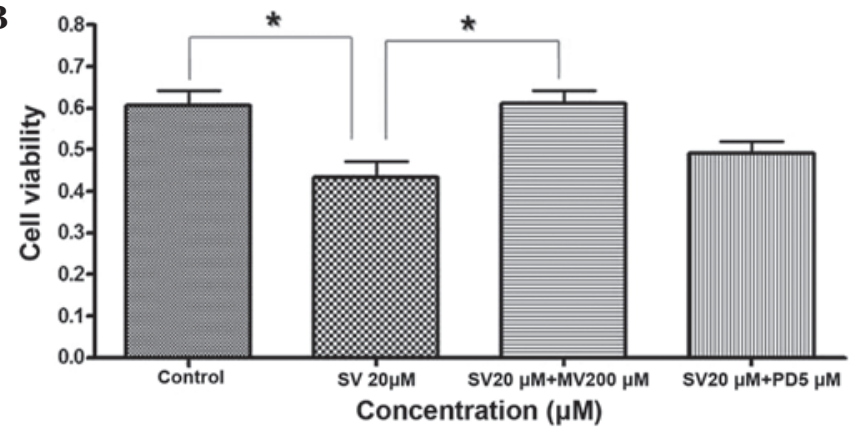

D

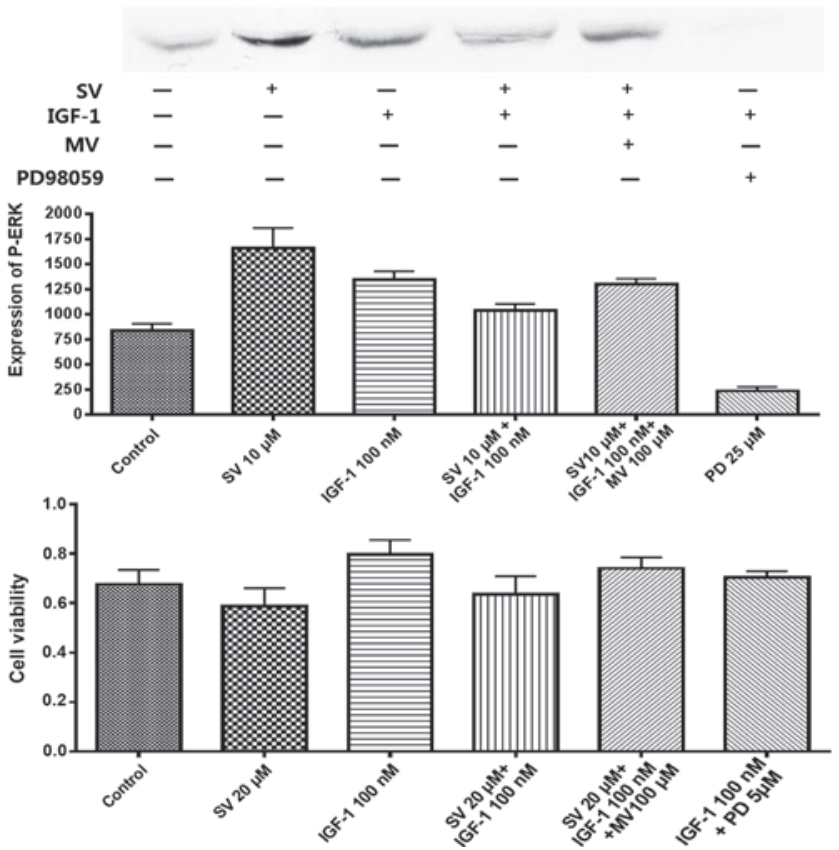

Figure 5. Effect of simvastatin on proapoptotic and anti-apoptotic ERK activation in HT-29 cells. (A) SV stimulated the expression of ERK, which is reversed by treatment with MV or PD. The cells were pretreated with $25 \mu \mathrm{M}$ PD or $100 \mu \mathrm{M} \mathrm{MV}$ for $2 \mathrm{~h}$ and then co-treated with $10 \mu \mathrm{M}$ SV for $24 \mathrm{~h}\left({ }^{*} \mathrm{P}<0.05\right.$ ). (B) Cell proliferation was suppressed by treatment with SV and then reversed by pretreatment with MV or PD. The cells were pre-treated with $200 \mu \mathrm{M} \mathrm{MV}$ or $5 \mu \mathrm{M}$ PD for $2 \mathrm{~h}$ and then co-treated with $20 \mu \mathrm{M} \mathrm{SV}$ for $48 \mathrm{~h}$ ( $(\mathrm{P}<0.05)$. (C) Caspase-3 activity was increased by treatment with SV and then suppressed by pretreatment of MV or PD under the aforementioned conditions ( $\left.{ }^{*} \mathrm{P}<0.05\right)$. (D) IGF-1 stimulated the expression of phosphorylated ERK and cell proliferation, which were suppressed by co-treatment with simvastatin. The cells were pretreated with or without $25 \mu \mathrm{M}$ PD or $100 \mu \mathrm{M}$ MV, or $10 \mu \mathrm{M}$ SV for $24 \mathrm{~h}$ and then exposed to $100 \mathrm{nM}$ IGF-1 for $15 \mathrm{~min}$. The effect of SV on IGF-1 induced ERK activation was reversed by treatment with MV or PD. P<0.001: Control vs. $10 \mu \mathrm{M} \mathrm{SV}$; control vs. IGF-1; control vs. SV+IGF-1+MV; control vs. PD; SV vs. SV+IGF-1; SV vs. PD; IGF-1 vs. PD; SV+IGF-1 vs. PD; and SV+IGF-1+MV vs. PD. P<0.01: SV vs. IGF-1; SV vs. SV+IGF-1+MV; P<0.05; control vs. SV+IGF-1; IGF-1 vs. SV+IGF-1; IGF vs. SV+IGF-1+MV; and SV+IGF-1 vs. SV+IGF-1+MV. The effect of simvastatin on IGF-1-induced cell proliferation was also reversed by treatment of MV or PD. P<0.001: Control vs. IGF-1; SV vs. IGF-1; SV vs. SV+IGF-1+MV; IGF-1 vs. SV+IGF-1; SV+IGF-1 vs. SV+IGF-1+MV; and SV vs. IGF-1+PD. P<0.01: Control vs. SV; and IGF-1 vs. IGF-1+PD. MV, mevalonate; SV, simvastatin; PD, PD98059; IGF-1, insulin-like growth factor 1; ERK, extracellular signal-regulated kinase; P-ERK, phosphorylated extracellular signal-regulated kinase.

content, including cell structural and functional elements, may inhibit cancer proliferation $(11,16,17)$. Several studies have investigated statin-attenuated IGF-1-induced ERK activation and cell proliferation in mesangial cells and prostate cancer cells $(16,17)$. One study demonstrated that fluvastatin inhibited IGF-1-induced MEK1/2 and ERK1/2 phosphorylation, mesangial cell proliferation and cyclin D1 expression (16). In another study, simvastatin was found to suppress proliferation and induce apoptosis of prostatic cancer cells, and to suppress the expression of IGF-1R. Knockdown of IGF-1R by siRNA resulted in the inhibition of proliferation of prostatic cancer cells. Simvastatin also inhibited IGF-1-induced activation of both ERK and Akt signaling and IGF-1-induced prostatic cancer cell proliferation (17). In another previous study, knockdown of IGF-1R by RNA interference in the colon cancer SW480 cell line suggested that decreasing the IGF-1R protein level could significantly inhibit tumor growth (18). These studies supported the present results that statin is a potent inhibitor of IGF-1R signaling system in colon cancer.

Notably, simvastatin induced ERK activation in addition to inhibiting IGF-1-induced ERK activation in HT-29 cells. The ERK1/2 cascade transmits mostly mitogenic signals and regulates growth factor-induced cell proliferation (19). The present results suggested that ERK may act differently, depending on the types of stimulating agents and the duration or strength of the signal. As a similar experimental result for time-dependent response, epidermal growth factor (EGF) and nerve growth factor (NGF) stimulate strong activation of ERK1/2 with distinct outcomes (20). EGF stimulation caused a transient activation of ERK1/2, peaking at $15 \mathrm{~min}$ and reducing back to basal levels after $40 \mathrm{~min}$, and induced cell proliferation in PC12 cells, while NGF stimulated sustained activation of 
ERK1/2 after 15-180 min, which resulted in the differentiation of cells (20). Previously, $\beta, \beta$-dimethylacrylshikonin induced mitochondria-dependent apoptosis through the ERK pathway in human gastric cancer SGC-7901 cells (21). Shen et al (21) suggested that sustained ERK activation induces apoptosis. In this study, a specific inhibitor of MEK blocked $\beta$, $\beta$-dimethylacrylshikonin-induced ERK activation and apoptosis in SGC-7901 cells (21). Kim et al showed that glucose deprivation induced adenosine monophosphate-activated kinase (AMPK) and proapoptotic ERK activation in HCT116 cells (22). AMPK protected HCT116 cells from glucose deprivation by suppressing proapoptotic ERK. From these results, it was found that ERK activation leads to cell proliferation, differentiation and apoptosis under various stimuli in various tissues.

Overall, the present study found that simvastatin induces apoptosis and suppresses the $\beta$ subunits of IGF-1R and IGF-1-induced ERK/Akt activation. The present results also demonstrated that simvastatin induces proapoptotic ERK activation, which antagonizes IGF-1-induced anti-apoptotic ERK activation in HT-29 cells. These results suggested that statins may be potential anti-cancer drugs against colon cancer due to proapoptotic ERK control.

\section{Acknowledgements}

The present study was supported by the Hallym University Medical Center (grant no. 01-2011-20).

\section{References}

1. Jahn KA, Su Y and Braet F: Multifaceted nature of membrane microdomains in colorectal cancer. World J Gastroenterol 17: 681-990, 2011.

2. Adachi Y, Yamamoto H, Ohashi H, Endo T, Carbone DP, Imai K and Shinomura Y: A candidate targeting molecule of insulin-like growth factor-I receptor for gastrointestinal cancers. World J Gastroenterol 16: 5779-5789, 2010.

3. Baserga R: The insulin-like growth factor I receptor: A key totumor growth? Cancer Res 55: 249-252, 1995.

4. Yu H and Rohan T: Role of the insulin-like growth factor family in cancer development and progression. J Natl Cancer Inst 92: 1472-1489, 2000.

5. Rodon J, DeSantos V, FerryRJ Jr and Kurzrock R: Early drug development of inhibitors of the insulin-like growth factor-Ireceptor pathway: Lessons from the first clinical trials. Mol Cancer Ther 7: 2575-2588, 2008.

6. Chen W, Wang S, Tian T, Bai J, Hu Z, Xu Y, Dong J, Chen F, Wang $\mathrm{X}$ and Shen $\mathrm{H}$ : Phenotypes and genotypes of insulin-like growth factor 1, IGF-binding protein-3 and cancer risk: Evidence from 96 studies. Eur J Hum Genet 17: 1668-1675, 2009.
7. Rinaldi S, Cleveland R, Norat T, Biessy C, Rohrmann S, Linseisen J, Boeing H, Pischon T, Panico S, Agnoli C, et al: Serum levels of IGF-I, IGFBP-3 and colorectal cancer risk: Results from the EPIC cohort, plus a meta-analysis of prospective studies. Int J Cancer 126: 1702-1715, 2010.

8. Dunn SE, Kari FW, French J, Leininger JR, Travlos G, Wilson R and Barrett JC: Dietary restriction reduces insulin-like growth factor I levels, which modulates apoptosis, cell proliferation, and tumor pogression in p53-deficient mice. Cancer Res 57: 4667-4672, 1997.

9. Wu Y, Yakar S, Zhao L, Hennighausen L and LeRoith D: Circulating insulin-like growth factor-I levels regulate colon cancer growth and metastasis. Cancer Res 62: 1030-1035, 2002.

10. Blais L, Desgagne' A and LeLorier J: 3-Hydroxy-3-methylglutaryl coenzymeA reductase inhibitors and the risk of cancer: A nested case-control study. Arch Intern Med 160: 2363-2368, 2000.

11. Graaf MR, Beiderbeck AB, Egberts AC, Richel DJ and Guchelaar HJ: The risk of cancer in users of statins. J Clin Oncol 22: 2388-2394, 2004.

12. Pollak M: Insulin and insulin-like growth factor signalling in neoplasia. Nat Rev Cancer 8: 915-928, 2008.

13. Gallagher EJ and LeRoith D: The proliferating role of insulin and insulin-like growth factors in cancer. Trends Endocrinol Metab 21: 610-618, 2010.

14. Reinmuth N, Fan F, Liu W, Parikh AA, Stoeltzing O, Jung YD, Bucana CD, Radinsky R, Gallick GE and Ellis LM: Impact of insulin-like growth factor receptor-I function on angiogenesis, growth, and metastasis of colon cancer. Lab Invest 82: 1377-1389, 2002.

15. LeRoith D and Roberts CT Jr: The insulin-like growth factor system and cancer. Cancer Lett 195: 127-137, 2003.

16. Shibata T, Tamura M, Kabashima N, Serino R, Tokunaga M, Matsumoto M, Miyamoto T, Miyazaki M, Furuno Y, Takeuchi M, et al: Fluvastatin attenuates IGF-1-induced ERK1/2 activation and cell proliferation by mevalonic acid depletion in human mesangial cells. Life Sci 84: 725-731, 2009.

17. Sekine Y, Furuya Y, Nishii M, Koike H, Matsui H and Suzuki K: Simvastatin inhibits the proliferation of human prostate cancer PC-3 cells via down-regulation of the insulin-like growth factor 1 receptor. Biochem Biophys Res Commun 372: 356-361, 2008.

18. Yavari K, Taghikhani M, Maragheh MG, Mesbah-Namin SA and Babaei MH: Knockdown of IGF-IR by RNAi inhibits SW480 colon cancer cells growth in vitro. Arch Med Res 40: 235-240, 2009.

19. Wortzel I and Seger R: The ERK cascade: Distinct functions within various subcellular organelles. Genes Cancer 2: 195-209, 2011.

20. Chung J, Kubota H, Ozaki Y, Uda $\mathrm{S}$ and Kuroda S: Timing-dependent actions of NGF required for cell differentiation. PLoS One 5: e9011, 2010.

21. Shen XJ, Wang HB, Ma XQ and Chen JH: $\beta, \beta$-Dimethylacrylshikonin induces mitochondria dependent apoptosis through ERK pathway in human gastric cancer SGC-7901 cells. PLoS One 7: e41773, 2012.

22. Kim MJ, Park IJ, Yun H, Kang I, Choe W, Kim SS and Ha J: AMP-activated protein kinase antagonizes pro-apoptotic extracellular signal-regulated kinase activation by inducing dual-specificity protein phosphatases in response to glucose deprivation in HCT116 carcinoma. J Biol Chem 285: 14617-14627, 2010. 